\title{
As grandes pandemias da história da Europa e os seus impactos na nossa civilização: desafios da moderna saúde pública
}

The major pandemics in the history of Europe and their impacts in our civilization: challenges of modern public health

Las grandes pandemias de la historia de Europa y sus impactos en nuestra civilización: desafíos de la salud pública moderna

Adalberto Campos Fernandes ${ }^{1}$

\section{Resumo}

A história das pandemias está intrinsecamente associada à evolução da humanidade. Ao longo do tempo, ocorreram sucessivos eventos de natureza pandémica, que condicionaram, em grande medida, o desenvolvimento dos povos. A história milenar das pandemias revela o caráter recorrente deste tipo de fenómeno. Nas últimas décadas, tem sido crescente a preocupação com o risco associado a doenças emergentes. As alterações decorrentes do modelo de desenvolvimento social e económico têm contribuído para um agravamento das desigualdades relativamente às condições de vida das populações. A concentração humana, com tendência à concentração urbana, a mobilidade, as questões relativas ao meio ambiente e ao comportamento humano persistem como fatores determinantes na defesa contra os diferentes tipos de ameaças. A pandemia causada pelo vírus Sars-Cov-2 pôs à prova, em termos globais, os níveis de preparação e a capacidade de reação dos diferentes países, revelando a fragilidade das respostas e a grande dificuldade na proteção dos grupos sociais mais expostos à doença. O mundo contemporâneo dispõe de instrumentos tecnológicos e de capacitação ao nível da investigação científica e da partilha de informação e geração de conhecimento, que o tornam mais forte e mais bem preparado para reagir a fenómenos biológicos inesperados. A moderna saúde pública terá de prevenir e antecipar riscos potenciais e emergentes, preparando os cidadãos e os sistemas de saúde para uma resposta robusta e adequada a este tipo de eventos.

\section{Palavras-chave}

Pandemias. Desenvolvimento Humano. Saúde Pública.

\begin{abstract}
The history of pandemics is intrinsically associated with the evolution of humanity. Throughout time, successive events of a pandemic nature, have occurred, which have largely conditioned the development of peoples. The millennial history of pandemics reveals the recurrent nature of this type of phenomenon. In recent decades, there has been growing concern about the risk associated with emerging diseases. The changes resulting from the model of social and economic development have contributed to worsening inequalities in relation to the living conditions of populations. Human concentration, mobility, the trend towards urban concentration, issues related to the environment and human behaviour persist as determining factors in the defence against different types of threats. The pandemic caused by the Sars-Cov-2 virus put to the test, in global terms, the levels of preparedness and

\footnotetext{
1 Professor Associado convidado, Departamento de Estratégias em Saúde, Escola Nacional de Saúde Pública, Universidade Nova de Lisboa, Lisboa, Portugal; Professor Catedrático convidado; Faculdade de Farmácia, Universidade de Lisboa, Lisboa, Portugal. Membro do Centro de Investigação em Saúde Pública (CISP) e do Comprehensive Health Research Centre (CHRC). https://orcid.org/0000-0003-3784-8198. E-mail: adalberto.fernandes@ensp.unl.pt
} 
response capacity of the different countries, revealing the fragility of the responses and the great difficulty in protecting the social groups most exposed to the disease. The contemporary world has technological instruments and capabilities at the level of scientific research and information sharing and knowledge generation, which make it stronger and better prepared to react to unexpected biological phenomena. Modern public health will have to prevent and anticipate potential and emerging risks, preparing citizens and health systems for a robust and appropriate response to such events.

\section{Keywords}

Pandemics. Human Development. Public Health.

\section{Resumen}

La historia de las pandemias está intrínsecamente asociada a la evolución de la humanidad. A lo largo del tiempo se han producido sucesivos acontecimientos de carácter pandémico que han condicionado en gran medida el desarrollo de los pueblos. La historia milenaria de las pandemias revela el carácter recurrente de este tipo de fenómenos. En las últimas décadas ha aumentado la preocupación por el riesgo asociado a las enfermedades emergentes. Los cambios derivados del modelo de desarrollo social y económico han contribuido a agravar las desigualdades en relación con las condiciones de vida de las poblaciones. La concentración humana, la movilidad, la tendencia a la concentración urbana, las cuestiones relacionadas con el medio ambiente y el comportamiento humano persisten como factores determinantes en la defensa contra distintos tipos de amenazas. La pandemia provocada por el virus Sars-Cov-2 puso a prueba, en términos globales, los niveles de preparación y capacidad de respuesta de los distintos países, revelando la fragilidad de las respuestas y la gran dificultad para proteger a los grupos sociales más expuestos a la enfermedad. El mundo contemporáneo dispone de herramientas tecnológicas y de desarrollo de capacidades en materia de investigación científica, intercambio de información y generación de conocimientos, que lo hacen más fuerte y mejor preparado para reaccionar ante fenómenos biológicos inesperados. La salud pública moderna tendrá que prevenir y anticiparse a los riesgos potenciales y emergentes, preparando a los ciudadanos y a los sistemas sanitarios para dar una respuesta sólida y adecuada a tales acontecimientos.

\section{Palabras clave}

Pandemias. Desarrollo Humano. Salud Pública.

\section{Introdução}

A Organização Mundial de Saúde define pandemia como um contexto de transmissão global e sustentada de uma dada doença cujo processo de difusão e de transmissão ocorre, simultaneamente, em vários países, regiões ou continentes. Esta definição comporta, no entanto, algumas limitações na medida em que tende a sobrevalorizar o critério da propagação em detrimento do critério da gravidade. (1)

A história das pandemias está profundamente interligada com a história da humanidade. Ao longo do tempo, ocorreram sucessivos acontecimentos de natureza pandémica, que condicionaram, em grande medida, o desenvolvimento dos povos. A grande maioria das pandemias resulta da ação de agentes patogénicos zoonóticos transmitidos aos 
seres humanos através do contacto com diferentes espécies de animais. O crescimento populacional e a sua dispersão pelo planeta criaram condições objetivas para a proliferação de doenças transmissíveis, que tiveram efeitos muito significativos na história dos povos. $(2,3)$

A história das pandemias é extraordinariamente rica na sua caracterização e na expressão dos seus efeitos desde a peste Antonina até à mais recente pandemia associada à COVID-19. Em geral, o aparecimento deste tipo de fenómeno tem como origem a dinâmica dos contactos entre humanos e animais, na mobilidade das populações e na concentração demográfica. A evolução das pandemias, ao longo dos séculos, define uma relação significativa entre as crises de saúde e as transformações sociais. $(4,5)$

Um dos aspetos determinantes, na generalização deste tipo de ocorrências, está relacionado com o crescimento do comércio e, consequentemente, com o aumento da mobilidade e da interação entre as pessoas. Nas últimas décadas, tem havido uma preocupação progressiva com o número crescente de surtos associados à transmissão de doenças infeciosas, sendo certo, no entanto, que este fenómeno sempre acompanhou a espécie humana, como os relatos históricos atestam há mais de dois mil anos. (6)

A tendência global para a concentração urbana contribuiu para o desenvolvimento de muitas doenças com elevado potencial de morbilidade e de mortalidade, como foi o caso, no passado, da varíola e como tem sido, no presente, o caso da tuberculose e da malária. A caracterização destes riscos levou que a abordagem epidemiológica deste tipo de doença se centrasse na redução dos contactos como um fator crítico no controlo dos surtos causados pelos diferentes tipos de agentes patogénicos. (7)

\section{Pandemias na história da humanidade}

A referência à maior pandemia, cujo conhecimento nos foi transmitido através dos relatos históricos, remete-nos na Antiguidade para a praga de Atenas, também conhecida como a praga do Egito. Na época, Atenas representava o centro da civilização grega e a fonte da criação filosófica e artística. Esta pandemia ocorreu entre os anos de 430 a.C. e 427 a.C., durante a Guerra do Peloponeso, tendo sido responsável por um elevado número de vítimas mortais cuja expressão terá ultrapassado, apenas na cidade de Atenas, dois terços da população. (8)

O impacto epidemiológico desta pandemia terá sido agravado pelo contexto de guerra o qual determinou um intenso movimento e aglomeração de pessoas, favorecendo, desse 


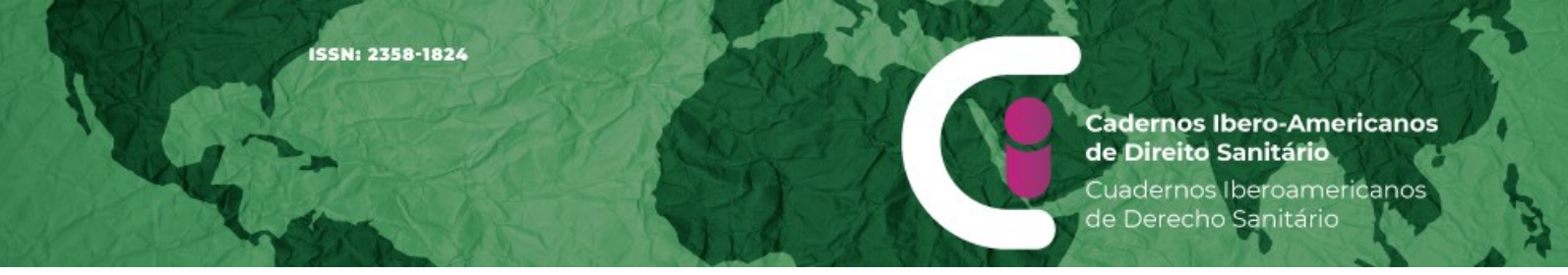

modo, a eclosão de cadeias de transmissão da doença. O general e historiador ateniano Tucídides deixou uma descrição detalhada desta praga através de um relato que teve grande importância na história do Ocidente. Apesar das diferentes teorias sobre a origem da doença, que consideravam como hipóteses prováveis a varíola, o sarampo e a peste bubónica, estudos recentes sugerem que a praga de Atenas tenha tido a febre tifoide como causa mais provável. $(9,10)$

No período compreendido entre os séculos II e III, o Império Romano foi atingido por duas grandes pragas - a peste Antonina também conhecida como a praga de Galeno, por volta do ano de 165 d.C. a qual, pese o facto da ausência de registos históricos robustos em relação ao agente etiológico, se pensa ter sido devido a um surto de varíola ou de sarampo o qual teria sido, inclusivamente, responsável pela morte do imperador romano Marco Aurélio. (11)

A peste de Cipriano, que ocorreu mais tarde, em 250 d.C., viu o seu nome associado ao bispo de Cartago. A causa desta pandemia permanece desconhecida, sendo referido o seu ponto de origem geográfica na região da Etiópia, espalhando-se mais tarde pelo Egito onde, apenas na cidade de Alexandria, terá vitimado mais de metade da população, antes de chegar a Roma. (12)

A expansão, no ano 444 d.C., para a Grã-Bretanha teve impactos muito importantes no enfraquecimento dos britânicos, forçando-os a estabelecer uma aliança com os saxões na luta contra os escoceses e os pictos. Do ponto de vista epidemiológico, persistem dúvidas quanto à etiologia da peste de Cipriano ganhando consistência a ideia de ter sido uma febre hemorrágica viral ou um outro tipo de infeção causada por um vírus. (13)

A praga de Justiniano ocorreu por volta do ano 541 d.C. e a sua designação deveuse ao nome do imperador bizantino da época. Esta pandemia teria começado no Egito para depois se espalhar para a capital do império bizantino. O primeiro surto de peste bubónica matou cerca de 50 milhões de pessoas, correspondente, na altura, a cerca de $26 \%$ da população mundial e a mais de metade da população europeia. (14)

A doença era transmitida através do contacto com pulgas e ratos contaminados, tendo sido responsável pela morte de cerca de um milhão de pessoas na cidade de Constantinopla. A extensão geográfica dos seus efeitos afetou grande parte dos territórios da Síria, da Turquia e da Pérsia bem como uma parte importante da Europa. A sua duração terá sido prolongada por cerca de dois séculos com impactos significativos, nas primeiras décadas da 
sua disseminação, nas estratégias de expansão do Império Romano a leste e à região norteafricana. (15)

No século $\mathrm{XI}$, a Europa foi atingida pela lepra, uma condição nosológica que mais tarde viria a ser designada como doença de Hansen. Neste período histórico, a doença era vista como um castigo divino prevalecendo a ideia de punição ou maldição. Os doentes eram vistos como uma ameaça, sendo sujeitos a um estrito isolamento com base, fundamentalmente, em convicções religiosas e ao medo da transmissão da doença. A maioria dos afetados morria isoladamente em lazaretos. Esta prática fez com que a imagem da lepra estivesse associada a uma doença marcada pelo medo e exclusão de pacientes em ambientes escuros e insalubres. (16)

O século XIV foi marcado por uma epidemia de proporções terríveis - a Peste Negra que mais tarde seria considerada a maior pandemia da história da civilização, resultando no extermínio de mais de um terço da população europeia. A epidemia começou em 1347 na Ásia Central, assumindo efeitos devastadores que persistiram até ao século XIX. A doença afetou por igual homens, mulheres, crianças, jovens e idosos, que sucumbiram a uma condição clínica marcada pela disseminação generalizada de pústulas e abcessos que os conduzia à morte num quadro de grande sofrimento. (17)

Os surtos recorrentes da doença condicionaram uma importante mudança demográfica na Europa. A Peste Negra ocorreu num período de transição da sociedade feudal para uma economia mercantil, marcada pelo aparecimento das cidades e do êxodo rural num contexto de confrontos e de escassez de recursos alimentares, associado a condições de higiene e de saúde extremamente deficientes.

A expansão urbana do século anterior sofreu um grave revés, resultando numa redução muito significativa das principais rotas comerciais sendo que, apenas na década de 1340, após mais de três séculos de sofrimento, a doença desapareceu tão inexplicavelmente como apareceu. Este período histórico ilustra de forma clara o impacto das doenças transmissíveis no desenvolvimento humano. $(17,18)$

Ao longo dos séculos, a Europa foi tradicionalmente permeável às doenças vindas do seu exterior, quer pelo efeito de guerras ou de invasões, quer pelo efeito da intensificação das rotas comerciais e da mobilidade das populações. A partir do século XV, a expansão marítima deu lugar a um fenómeno inverso, caracterizado pela transmissão de doenças em diferentes geografias, pelos europeus aos povos colonizados. (19) 
Os efeitos da expansão marítima e territorial ligada à colonização foram devastadores para a maioria das populações indígenas dos territórios alcançados. Um dos exemplos mais impressionantes foi o extermínio das populações nativas da América Central. Em 1519, estimava-se que viveriam na América Central cerca de 15 a 30 milhões de nativos locais, antes da chegada dos colonos espanhóis, e que esse número teria sido reduzido para menos de dois milhões no final do século XVI. (20)

A transmissão de doenças trazidas pelos europeus teve um forte impacto nas regiões mais populosas do antigo Império Maia, bem como nos diferentes territórios das Caraíbas. Um exemplo descrito deste tipo de ocorrência é ilustrado pelo impacto da chegada de Cristóvão Colombo à América, em 1496. Nesta região, a população indígena das Caraíbas representaria cerca de 60 mil pessoas, tendo este número diminuído para menos de 500 em 1548, em resultado da ocorrência de doenças como o sarampo e a peste bubónica as quais foram responsáveis pela morte de cerca de $90 \%$ da população. Os factos ocorridos ao longo do período da expansão marítima, resultantes da busca do novo mundo pelos povos europeus, revelam os efeitos das doenças, em termos globais, na forma como a globalização se iniciou no mundo, nomeadamente, no efeito que as doenças transmissíveis tiveram no processo histórico. (20)

A história das pandemias foi igualmente marcada, em 1580, pelos primeiros relatórios associados aos vírus da gripe na Ásia, Europa, África e América com efeitos muito graves, que causaram a morte de cerca de $10 \%$ da população nas áreas afetadas pela doença. Em 1665, ocorreu a grande praga de Londres durante a qual a peste bubónica foi responsável pela morte de cerca de $20 \%$ da sua população. Em 1729 e em 1732, na Rússia, ocorreram epidemias de gripe que causaram mais 500 mil mortes. Em 1781 e em 1830, novas pandemias de gripe foram reportadas na China as quais se estenderam à Europa e às Américas, infetando mais de $25 \%$ da população. (21)

No início do século XIX, mais precisamente em 1817, surgiu o primeiro grande surto de cólera. Em 1832 e 1852, registaram-se novas epidemias de cólera que começaram na Europa e se expandiram para outros continentes, causando mais de um milhão de mortes. Em 1855, começou a terceira onda da pandemia da peste bubónica, a partir da China com a propagação para o Sudeste Asiático, que se estima ter causado um número de mortos superior a 15 milhões de pessoas. As condições de insalubridade foram determinantes, neste período histórico, para a recorrência deste tipo de pandemias. Um dos aspetos mais 
importantes referia-se à ausência de hábitos de higiene pessoal que agravavam o potencial de transmissão de doenças infeciosas. $(22,23)$

Em 1889, a gripe russa emergiu a partir da Sibéria espalhando-se de seguida por toda a Europa, América do Norte e África. Em 1890, a gripe russa teve como consequência um número de vítimas superior a 350 mil. Em 1892 e em 1899 surgiram novos surtos com extensão à Europa com particular incidência na Alemanha. (24)

Em 1918, surgiu a gripe espanhola que assolou o mundo entre 1918 e 1919. Embora a origem geográfica desta pandemia seja desconhecida, tornou-se conhecida como gripe espanhola, gripe pneumónica, peste pneumónica ou simplesmente pneumonia. A pandemia da gripe espanhola afetou cerca de 500 milhões de pessoas e causou cerca de 50 a 100 milhões de mortes. De acordo com alguns autores, a pandemia teria tido como ponto de origem um campo militar no Kansas, Estados Unidos, espalhando-se entre os militares que mais tarde viajaram para a Europa. A gripe espanhola é considerada a maior pandemia conhecida no mundo até à data. A mortalidade associada a esta pandemia ultrapassou a Peste Negra ao longo de vários séculos e representou quase o triplo do número de mortes na Primeira Guerra Mundial. $(25,26)$

A principal razão para o elevado número de vítimas mortais está associada ao facto de a guerra existente gerar uma grande concentração de militares, facilitando a propagação do vírus e propiciando condições ideais para o desenvolvimento e a transmissão de estirpes mais agressivas. Esta será também a explicação para justificar a elevada mortalidade entre os indivíduos com idades compreendidas entre os 20 e os 40 anos.

Em 1957, emergiu a Gripe Asiática, uma das maiores epidemias de gripe do mundo, cuja origem geográfica foi referenciada ao norte da China com rápida expansão para Singapura e Hong Kong e, posteriormente, para outros continentes, tendo sido responsável por mais de 1 milhão de mortes em todo o mundo. Em 1961, a pandemia da gripe surgiu na Indonésia, tendo-se espalhado depois para o continente asiático. Em 1968, a gripe de Hong Kong foi responsável por um forte impacto na guerra do Vietname com rápida difusão pelo mundo, tendo causado cerca de um milhão de mortes. (27)

\section{Pandemias no século XXI}

A evolução das pandemias, ao longo do tempo e da história, demonstra similaridades que se foram repetindo. A concentração humana, a mobilidade, a tendência de concentração urbana, as questões relativas ao meio ambiente e ao comportamento humano persistem 
como fatores determinantes na defesa contra os diferentes tipos de ameaças. $O$ mundo mudou, significativamente, em resultado da investigação científica e da impressionante acumulação de conhecimento. No entanto, apesar da evolução extraordinária nos diferentes domínios económicos, sociais, sanitários, ambientais e culturais subsistem vulnerabilidades face à emergência de riscos globais.

Em 2009, a pandemia da gripe A surgiu como uma variante da gripe suína. Os primeiros casos foram identificados no México em março de 2009, chegando à Europa e à Oceânia pouco tempo depois. Esta pandemia, causada pelo vírus $\mathrm{H} 1 \mathrm{~N} 1$, resultou em mais de 200.000 mortes em todo o mundo, afetando, principalmente, indivíduos mais jovens com idades compreendidas entre os 5 e os 24 anos. Atualmente, persistem no mundo doenças transmissíveis como o Ébola, o Zika, o Dengue e o Chikungunya, que merecem permanente atenção das autoridades sanitárias pelo risco associado ao seu potencial de transmissão. $(28,29)$

\section{Desafios da moderna saúde pública}

A crise da pandemia, associada ao COVID-19, pôs em evidência as vulnerabilidades do mundo moderno face a riscos emergentes. A humanidade foi confrontada com uma situação inesperada de proporções globais e efeitos devastadores, tanto em termos de saúde como em termos económicos. A importância da saúde pública, enquanto disciplina científica orientada para a proteção e melhoria da saúde das pessoas e das comunidades, tornou-se clara. (30)

A pandemia causada pelo vírus Sars-Cov-2 pôs à prova os dispositivos de saúde pública em todo o mundo. De uma forma geral, ficou claro que a capacitação dos países é, em grande medida, independente do seu nível de desenvolvimento social e económico. A evolução da pandemia, associada ao COVID-19, demonstrou a fragilidade das respostas e a grande dificuldade na proteção dos grupos sociais mais expostos à ação fisiopatológica do vírus. (31)

A história milenar das pandemias que afetou a humanidade mostra que estamos perante fenómenos cíclicos e recorrentes. O mundo moderno afirma uma tendência progressiva para a concentração populacional em ambientes urbanos de elevada densidade populacional, associada a uma intensa mobilidade entre países e continentes, o que torna especialmente preocupante a ocorrência de novos eventos associados a doenças transmissíveis emergentes. (32) 
A partir desta crise, reconhecemos o importante papel da globalização na vida real das pessoas e dos países. O modelo de desenvolvimento social e económico do mundo contemporâneo irá acentuar cada vez mais a agregação populacional nas grandes cidades e a mobilidade entre países e continentes. Os processos de transição demográfica e epidemiológica, associados aos riscos emergentes de doenças transmissíveis de natureza global, trazem novos desafios estratégicos, bem como a necessidade de um pensamento diferente sobre os modelos de resposta, tanto no domínio da prevenção como da gestão dos riscos, como no controlo e monitorização de eventos inesperados e difíceis de prever. (33)

A crise pandémica veio acentuar a necessidade de cooperação e colaboração entre países e níveis de governação e de administração. A criação progressiva de ambientes urbanos saudáveis passou a fazer parte das prioridades políticas nos diferentes países. $O$ envolvimento das cidades e das comunidades locais na implementação das estratégias e das políticas de saúde tornará mais sustentável o desenvolvimento social e económico. (34)

O mundo contemporâneo tem instrumentos, em termos de desenvolvimento tecnológico de investigação científica e de partilha de informação e conhecimento, que o tornam mais forte e mais bem preparado para reagir a fenómenos biológicos inesperados. A consolidação dos mecanismos de proteção da saúde, de melhoria da qualidade de vida, de vigilância e controlo das doenças transmissíveis bem como da melhor gestão da doença crónica e de enquadramento da transição demográfica passará por uma aposta estratégica de proximidade com base em políticas integradas. (35)

A próxima década ficará marcada pela transição das políticas tendo em vista a centralidade no indivíduo, a participação ativa e a responsabilidade partilhada. A saúde está fortemente relacionada com a forma como são geridas as questões ambientais, a mobilidade, o nível de educação e informação das populações, as condições de trabalho e de lazer entre muitas outras.

A crise associada ao COVID-19 mostrou a necessidade de estratégias de saúde inclusivas e multissetoriais. Um pouco, em todo o lado, fica evidente a importância de respostas articuladas, centradas nas pessoas, tendo em vista a eficácia dos resultados num contexto de planeamento dos recursos, a fim de salvaguardar a proteção específica da saúde através da cobertura geral e universal dos cuidados de saúde. (36)

O caminho assinalado pelos Objetivos de Desenvolvimento Sustentável (ODS) requer políticas de proximidade, o aumento da literacia em saúde pelos cidadãos, bem como ações promotoras de uma maior participação cívica e da adoção de comportamentos favoráveis à 
saúde. A integração das políticas de promoção da saúde nos modelos de governação e de gestão local contribuirá para a melhoria das condições de vida com um impacto significativo nas zonas urbanas. (37)

A moderna saúde pública terá de ser capaz de prevenir e antecipar riscos potenciais e emergentes, preparando os cidadãos e os sistemas de saúde para uma resposta adequada a este tipo de eventos, aprofundando a capacidade de investigação científica e criando condições para que a transmissão inadequada de agentes da doença seja monitorizada e controlada. (38)

\section{Referências}

1. De Campos TC. The Traditional Definition of Pandemics, Its Moral Conflations, and Its Practical Implications: A Defense of Conceptual Clarity in Global Health Laws and Policies. Vol. 29, Cambridge Quarterly of Healthcare Ethics. 2020. p. 205-17.

2. Piret J, Boivin G. Pandemics Throughout History. Vol. 11, Frontiers in Microbiology; 2021.

3. LePan N. Visualizing the History of Pandemics. Vis Hist Pandemics [Internet]. 2020;2:116. Available from: https://www.visualcapitalist.com/history-of-pandemics-deadliest/

4. Madhav N, Oppenheim B, Gallivan M, Mulembakani P, Rubin E, Wolfe N. Pandemics: Risks, Impacts, and Mitigation. In: Disease Control Priorities: Improving Health and Reducing Poverty. Third Edition (Volume 9); 2017.

5. Gullot CC, Serpa GR. Major pandemics in the history of mankind. Vol. 92, Revista Cubana de Pediatria. 2020.

6. Jarus O. 20 of the Worst Epidemics and Pandemics in History. Live Sci. 2020;(12).

7. Moslonka-Lefebvre M, Monod H, Gilligan CA, Vergu E, Filipe JAN. Epidemics in markets with trade friction and imperfect transactions. J Theor Biol. 2015;374.

8. Hernández-Mesa N, Llanes JH, Betancourt CL. Major epidemics in human history. From the Plague of Athens to COVID-19. Rev Habanera Ciencias Medicas. 2020;19(5).

9. Littman RJ. The plague of Athens: Epidemiology and paleopathology. Mount Sinai Journal of Medicine. 2009;(76).

10. Papagrigorakis MJ, Yapijakis C, Synodinos PN, Baziotopoulou-Valavani E. DNA examination of ancient dental pulp incriminates typhoid fever as a probable cause of the Plague of Athens. Int J Infect Dis. 2006;10(3).

11. Sabbatani S, Manfredi R, Fiorino S. The Justinian plague (part one). Infez Med. 2012;20(2). 
12. Cravioto EG, García IG. The pest in Antiquity. Historiographical origins. Vol. 18, Revista de Historiografia. 2013.

13. Geoffroy AS, Díaz JP. From the antonine plague to the cyprian plague: Scopes and consequences of global plagues in the Roman empire in the 3rd century ad. Rev Chil Infectol. 2020;37(4).

14. Sang DL. The First Pandemic in History: The Justinian Plague. Crit Rev Hist. 2020;132.

15. Sabbatani S, Fiorino S. [The Antonine Plague and the decline of the Roman Empire]. Infez Med. 2009;17(4).

16. Gilmore JK. Leprosy at the Lazaretto on St. Eustatius, Netherlands Antilles. Int J Osteoarchaeol. 2008;18(1).

17. Slack P. Plague: Black Death and Pestilence in Europe. Engl Hist Rev. 2004;119(483).

18. Jeuneman F. The Black Plague. Res Dev. 1998;40(13).

19. Crosby AW, Cook ND. Born to Die: Disease and New World Conquest, 1492-1650.

Popul Dev Rev. 1998;24(3).

20. Pringle H. How Europeans brought sickness to the New World. Science (80- ). 2015.

21. Johnson R. The 10 Epidemics That Almost Wiped Out Mankind. The Business Insider. 2011.

22. Lippi D, Gotuzzo E, Caini S. Cholera: A history of pandemics. In: Microbiology spectrum; 2016.

23. Ashworth W, Lewis RA. Edwin Chadwick and the Public Health Movement, 1832-1854. Econ Hist Rev. 1953;5(3).

24. Roy P, Islam SR, Rahman F, Siddiqui MMR. Avian Influenza \& Human Health. Anwer Khan Mod Med Coll J. 2014;5(1).

25. Aassve A, Alfani G, Gandolfi F, Le Moglie M. Epidemics and trust: The case of the Spanish Flu. Heal Econ. 2021.

26. Rosenbert J. 1918 Spanish Flu Pandemic. Thought Co. 2019;(April 2018).

27. Yoshikura H. Spanish flu, asian flu, hong kong flu, and seasonal influenza in Japan under social and demographic influence: Review and analysis using the two-population model. Japanese Journal of Infectious Diseases. 2014;(67).

28. Sabharwal S, Mahajan A, Gupta SK. Swine influenza A (H1NI virus) flu or common cold. JK Science. 2009;(11). 


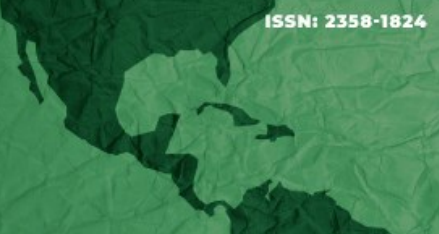

29. Fritzell C, Rousset D, Adde A, Kazanji M, Van Kerkhove MD, Flamand C. Current challenges and implications for dengue, chikungunya and Zika seroprevalence studies worldwide: A scoping review. PLoS Negl Trop Dis. 2018;12(7).

30. Sheehan MC, Fox MA. Early Warnings: The Lessons of COVID-19 for Public Health Climate Preparedness. Int J Heal Serv. 2020;50(3).

31. Schellekens P, Sourrouille D. COVID-19 Mortality in Rich and Poor Countries: A Tale of Two Pandemics? 2020.

32. Megahed NA, Ghoneim EM. Antivirus-built environment: Lessons learned from Covid2020.

33. Venkatesan $P$. The changing demographics of COVID-19. The Lancet. Respiratory medicine. 2020;( 8).

34. Shamdasani P, Trubiano JA, Smibert OC, Owen CE, Liew DFL. COVID-19:

collaboration will keep us ahead of the curve. Internal Medicine Journal. 2020;(50).

35. WHO. Emergencies preparedness, response. 2018;2(April 1997).

36. Lal A, Erondu NA, Heymann DL, Gitahi G, Yates R. Fragmented health systems in COVID-19: rectifying the misalignment between global health security and universal health coverage. Vol. 397, The Lancet. 2021.

37. Will the COVID-19 pandemic threaten the SDGs? The Lancet Public Health. 2020;(5).

38. Kumar S, Poonam, Rathi B. Coronavirus Disease COVID-19: A New Threat to Public Health. Curr Top Med Chem. 2020;20(8).

\section{Como citar este artigo}

Fernandes AC. As grandes pandemias da história da Europa e os seus impactos na nossa civilização: desafios da moderna saúde pública. Cadernos Ibero-Americanos de Direito Sanitário. 2021 abr./jun.;10(2):19-30. 